\title{
Klasifikasi Kematangan Pada Buah Mangga Garifta Merah dengan Transformasi Ruang Warna HSI
}

\author{
Ahmad Muslih Syafi'i ${ }^{1}$, Muhammad Fajar Ahadi ${ }^{2}$, Muhammad Iqbal Rasyid ${ }^{3}$, \\ Faisal Dharma Adhinata ${ }^{4}$, Apri Junaidi ${ }^{5}$ \\ Rekayasa Perangkat Lunak, Fakultas Informatika, Institut Teknologi Telkom Purwokerto \\ Sains Data, Fakultas Informatika, Institut Teknologi Telkom Purwokerto \\ 19104034@ittelkom-pwt.ac.id ${ }^{1}$, 19104007@ittelkom-pwt.ac.id ${ }^{2}$, 19104041@ittelkom-pwt.ac.id $^{3}$, \\ faisal@ittelkom-pwt.ac.id ${ }^{4}$, apri@ittelkom-pwt.ac.id $^{5}$
}

\section{Article Info \\ Article history: \\ Received 2021-08-01 \\ Revised 2021-08-29 \\ Accepted 2021-09-25}

Keywords:

Fruit,

Garifta Mango,

HSI color,

Ripeness detection.

\begin{abstract}
Garifta Mango is obtained from the combination of the best quality local mangoes. Garifta mango is said to have a sweeter taste variant than the quality of other types of mango. However, when choosing Red Garifta mangoes with a good level of ripeness, we are often confused. Sometimes Red Garifta mango entrepreneurs still use manual methods to distinguish the ripeness of Red Garifta mangoes. Therefore, this study carried out a systematic design using the HSI color space transformation method. We used 15 Red Garifta mangoes as test data and 30 Red Garifta mangoes as training data in the testing phase. After doing the test, we get the accuracy, precision, and recall of 15 test data, respectively $80 \%, 80 \%$, and $87 \%$. From this percentage value, it can be concluded that the method we use can be used to detect the ripeness of the Red Garifta mango fruit.
\end{abstract}

\section{Pendahuluan}

Mangga menjadi buah tropis yang sangat populer di berbagai negara. Buah tropis yang paling populer, bersama dengan durian yang dikenal sebagai raja buah. Khususnya di Indonesia sendiri merupakan pusat dan sumber berbagai jenis buah tropis dan keanekaragaman hayatinya. Salah satu jenis buah tropis terbaru yang dikembangkan adalah mangga Garifta.[1]

Mangga Garifta didapatkan dari hasil perpaduan antar mangga lokal berkualitas terbaik. Menurut Rebin memaparkan bahwasannya Mangga Garifta dikatakan mempunyai varian rasa lebih manis dibandingkan kualitas mangga dengan jenis lainnya. Buah mangga Garifta mencakup dari berbagai jenis antara lain: Garifta Merah, Garifta Oranye, Garifta Gading, dan Garifta Kuning.[2]

Mangga Garifta Merah adalah buah yang menarik dengan kulit kuning-merah, aroma yang kaya, rasa segar, dan keasaman total $0,21 \%$. Mangga Garifta Merah memiliki penampilan yang menarik dengan tekstur buah yang agak lunak dan serat yang halus.[3]

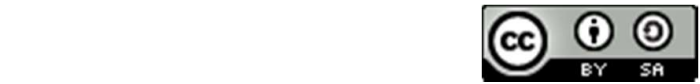

This is an open access article under the CC-BY-SA license.
Namun, ketika memilih mangga Garifta Merah dengan tingkat kematangan yang baik, seringkali kita bingung. Terkadang pengusaha mangga Garifta Merah masih memakai cara manual untuk memilah kematangan mangga Garifta Merah, sedangkan cara yang digunakan oleh pekerja seringkali kurang tepat dan penentuannya berbeda-beda. Perbedaan ini disebabkan oleh perbedaan persepsi setiap manusia.[4]. Berdasarkan permasalahan tersebut, pada penelitian ini kami membuat perancangan sistem yang dapat mengklasifikasi kematangan Mangga Garifta. Dengan memakai metode transformasi ruang warna HSI, diharapkan bisa membantu pengusaha dalam menyortir buah mangga garifta merah baik yang matang, setengah matang ataupun mentah.

Pada perancangan sistem klasifikasi kematangan buah mangga garifta merah ini meliputi: Pengolahan Citra, Ruang Warna, RGB, HSI, Preprocessing Citra, Segmentasi Citra dan Confusion Matrix.

Pengolahan Citra adalah proses untuk mengolah dan menganalisis citra yang menyertakan banyak pemahaman visual. Teknik ini memiliki karakteristik memasukkan data dan mengeluarkan informasi berupa gambar [5]. Setelah

http://jurnal.polibatam.ac.id/index.php/JAIC 
menganalisis citra yang telah diproses, selanjutnya membutuhkan metode ruang warna. Ruang warna adalah suatu metode dalam mengatur, menciptakan, dan memvisualisasikan warna. Biasanya metode ini digunakan untuk menguraikan gambar. Ruang warna ini meliputi: RGB, HSL, HSV, HSI, dll [6]. RGB dilandaskan pada konsep peningkatan cahaya esensial yang solid, yaitu Red, Green, dan Blue. Di ruangan tanpa cahaya sama sekali, ruangan benarbenar gelap. Ketika menambahkan lampu merah ke ruangan, warna ruangan akan menjadi warna merah, seperti $(R, G, B)$ $(255,0,0)$. Demikian pula jika menggunakan hijau atau biru sebagai pengganti cahaya [7]. Ruang warna HSI menentukan warna berdasarkan Hue, Saturation, dan Intesity. Hue diperlukan dalam membedakan warna dan menentukan warna merah, hijau, dan lain sebagainya berdasarkan cahaya. Saturation menunjukkan tingkat kemurnian warna, dan menunjukkan seberapa putih warnanya. Intensity adalah properti yang mewakili jumlah cahaya yang diterima oleh mata, terlepas dari warnanya [8].

Preprocessing adalah pengolahan data citra yang berbentuk digital, sehingga data tersebut bisa dan cukup untuk tahap selanjutnya. Langkah-langkah preprocessing perlu dilakukan untuk memastikan kelancaran proses selanjutnya, antara lain: Peningkatan kualitas gambar, Menghilangkan warna citra yang mengganggu, Pemulihan gambar, Transformasi, dan Tentukan persentase citra yang akan diamati. Setelah melakukan preprocessing citra kemudian di lanjut dengan Segmentasi, dimana segmentasi ini merupakan potongan dari preprocessing dengan tujuan untuk memecah beberapa objek yang dibutuhkan dengan objek yang tidak dibutuhkan [9].

Untuk menganalisis apakah pengklasifikasi pandai mengidentifikasi tupel dari kelas yang berlainan dengan Confusion Matrix. Nilai True Positive dan True Negative memberikan laporan ketika classifier mengklasifikasikan data, sedangkan False Positive dan False Negative memberikan laporan ketika classifier mengklasifikasikan data secara tidak benar. Confusion Matrix meliputi accuracy, precision, dan recall [10]. Accuracy ialah perbandingan antara data yang diklasifikasikan dengan benar dengan seluruh data. Precision menunjukkan jumlah data positif yang diklasifikasikan dengan benar dibagi dengan jumlah total data yang diklasifikasikan sebagai positif. Recall menunjukkan berapa persentase data golongan positif yang diklasifikasikan dengan benar oleh sistem[11].

Penelitian tentang kematangan buah mangga dilakukan oleh Indarto menggunakan transformasi warna untuk penelitian pendeteksiannya yang judul "Deteksi Kematangan Buah Pisang Berdasarkan Fitur Warna Citra Kulit Pisang Menggunakan Metode Transformasi Ruang Warna HSI" [8]. Hasil yang diperoleh pada penelitian ini adalah akurasi konsistensi 20 sampel buah (termasuk 10 buah pisang ambon belum masak dan 10 buah pisang ambon matang) dengan metode HIS sebesar $85 \%$.

Penelitian pendeteksian jenis warna kulit wajah untuk klasifikasi ras manusia menggunakan transformasi warna [12]. Hasil dari penelitian tersebut adalah menerapkan metode transformasi warna menunjukkan tingkat akurasi yang sangat baik, dengan menggunakan 20 sampel wajah dari ras yang berbeda mencapai rata-rata $85 \%$.

Transformasi warna untuk penelitian pendeteksian dalam menerapkan metode transformasi ruang warna Hue Saturation Intensity (HSI) untuk mendeteksi kematangan buah mangga [9]. Hasil penelitian tersebut telah diuji dengan menggunakan 20 sampel data yang terdiri dari 10 sampel latih berupa citra mangga masak dan 10 sampel uji yang terdiri dari 5 sampel mangga matang dan 5 sampel mangga belum matang. 87\%, sehingga dapat disimpulkan bahwa metode transformasi ruang warna HSI dapat digunakan untuk mendeteksi kematangan buah mangga Harum Manis.

Maka dari itu penelitian ini melakukan perancangan sistematik dengan memakai metode Transformasi Ruang Warna HSI untuk klasifikasi tingkat kematangan buah mangga Garifta Merah. Dengan menggunakan cara ini, dimungkinkan dapat membantu para pengusaha mangga dalam memilih mangga jenis Garifta Merah yang sudah matang.

\section{Metode}

Pada metode penelitian ini ada beberapa tahap untuk mencapai tujuan pada penelitian ini adalah pengumpulan data, membuat program dan pengujian.

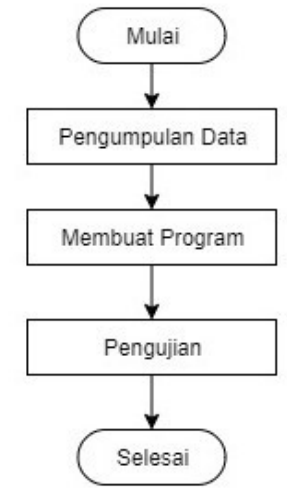

Gambar 1. Flowchart Proses

Proses pertama mengumpulkan data, Data di penelitian ini diperoleh dengan cara penelusuran literatur. Dari studi literatur, didapatkan dari semua literatur yang berkaitan dengan topik seperti pengolahan citra dan warna buah mangga garifta merah, metode ini merupakan sumber referensi untuk merancang program yang akan dibuat. Cara ini diperlukan untuk memastikan bahwa data yang diperoleh untuk buah mangga garifta sesuai dengan data yang tersedia, seperti gambar buah mangga Garifta Merah matang, buah mangga Garifta Merah setengah matang dan buah mangga Garifta Merah mentah.

Data Mangga Garifta didapat melalui website kaggle.com yang dimana kami mengambil masing-masing 10 gambar sebagai data latih dan masing-masing 5 gambar sebagai data uji. Data yang digunakan dapat dilihat pada Tabel I. 
TABEL I

JUMLAH DATA LATIH DAN UJI

\begin{tabular}{|lc|c|c|}
\hline & & Data Latih & Data Uji \\
\hline $\begin{array}{l}\text { Mangga Garifta } \\
\text { Mentah }\end{array}$ & 10 buah & 5 buah \\
\hline $\begin{array}{l}\text { Mangga Garifta } \\
\text { Setengah Matang }\end{array}$ & 10 buah & 5 buah \\
\hline $\begin{array}{l}\text { Mangga Garifta Merah } \\
\text { Matang }\end{array}$ & 10 buah & 5 buah \\
\hline
\end{tabular}

TABEL III

DATA UJI

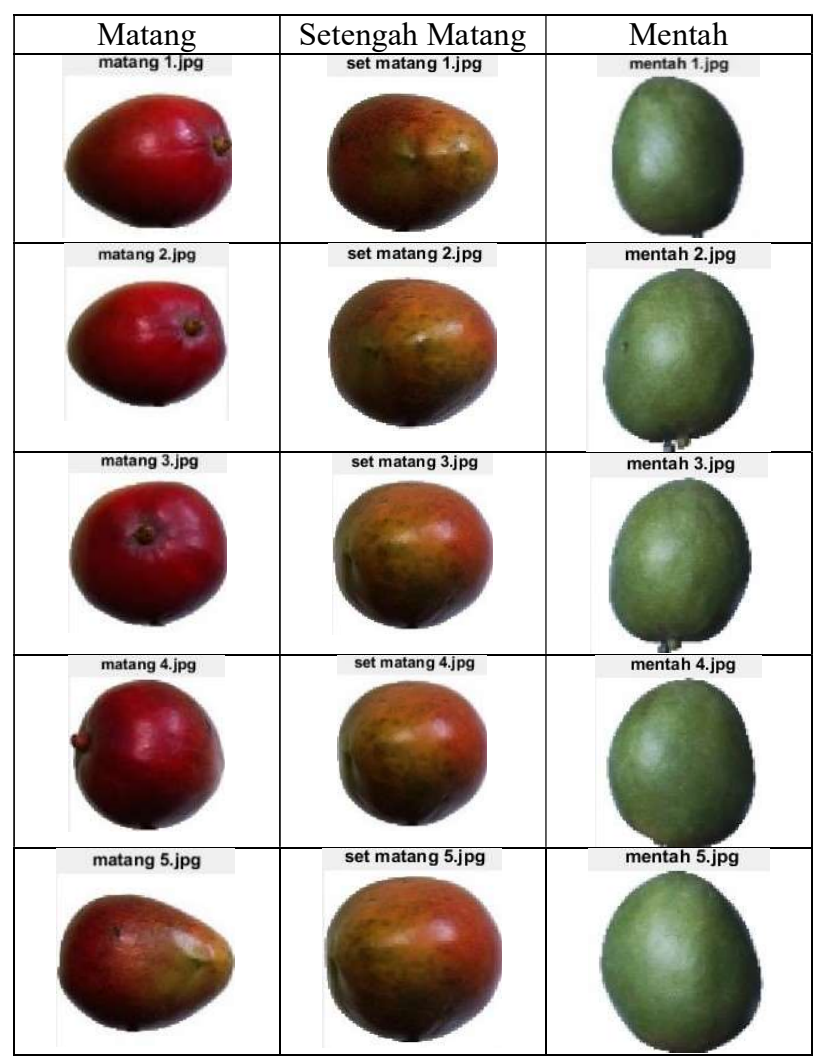

Proses kedua membuat programnya, disini kami membuatnya dengan menggunakan bahasa pemrograman MATLAB. Sebelum melakukan pengujian, kami memasukkan data latih terlebih dahulu ke dalam program tersebut yang dimana nantinya data latih itu akan dijadikan sebagai referensi. Kemudian dilanjutkan dengan pengujian. Gambar 2 menunjukkan flowchart dari proses pengujian.

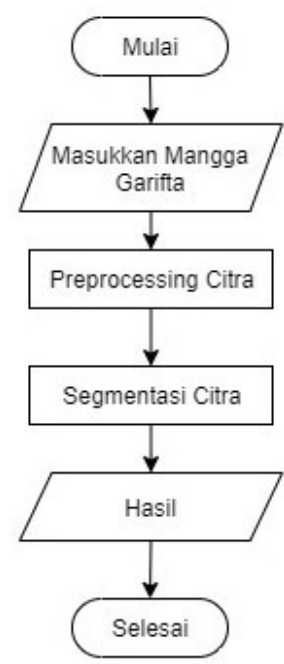

Gambar 2. Flowchart Pengujian

Pertama, kami memasukan data uji ke dalam program yang dibuat berupa buah Mangga Garifta yang sudah berformat jpg. Kemudian program melakukan proses preprocessing citra yang dimana citra RGB di transformasi ke citra HSI dengan menggunakan rumus sebagai berikut:

$$
\begin{gathered}
H= \begin{cases}\theta & \text { if } \mathrm{B} \leq \mathrm{G} \\
360-\theta & \text { if } \mathrm{B}>\mathrm{G}\end{cases} \\
\theta=\cos ^{-1}\left\{\frac{\frac{1}{2}[(R-G)+(R-B)]}{\left[(R-G)^{2}+(R-B)(G-B)\right]^{\frac{1}{2}}}\right\} \\
S=1-\frac{3}{(\mathrm{R}+\mathrm{G}+\mathrm{B})}[\min (\mathrm{R}, \mathrm{G}, \mathrm{B})] \\
I=\frac{1}{3}(\mathrm{R}+\mathrm{G}+\mathrm{B})
\end{gathered}
$$

Selanjutnya proses segmentasi citra. Setelah di transformasikan menjadi citra HSI, citra HSI dipisahkan antara buah Mangga garifta dengan backgroundnya. Kemudian citra tersebut akan di cocokkan dengan citra data latih yang sudah dimasukan terlebih dahulu dan nanti akan keluar hasilnya antara matang, setengah matang, dan mentah.

\section{Hasil dan Pembahasan}

Pada tahap pengujian, kami menggunakan 15 buah mangga Garifta Merah sebagai data uji. Kemudian data uji dimasukkan ke dalam program yang telah dibuat. Dalam program tersebut, terdapat 30 data buah mangga Garifta Merah yang telah dilatih sebelumnya. Dari 15 data uji, 3 data mengalami kesalahan saat melakukan pengujian yaitu data buah mangga Garifta Merah setengah matang. Setelah dilakukan pengujian pada data pengujian, hasil pengujian dapat dilihat pada Tabel III. 
TABEL III

Hasil Pengujian

\begin{tabular}{|c|c|c|c|c|c|}
\hline \multirow[b]{2}{*}{ Data Uji } & \multicolumn{3}{|c|}{ Pengujian } & \multirow{2}{*}{ Hasil } & \multirow{2}{*}{ Keterangan } \\
\hline & $\mathbf{H}$ & $\mathbf{S}$ & I & & \\
\hline Mangga 1 & 0,109323 & 0,35232 & 0,39382 & Matang & Benar \\
\hline Mangga 2 & 0,113866 & 0,357534 & 0,38912 & Matang & Benar \\
\hline Mangga 3 & 0,101795 & 0,340111 & 0,36954 & Matang & Benar \\
\hline Mangga 4 & 0,097502 & 0,324949 & 0,365428 & Matang & Benar \\
\hline Mangga 5 & 0,115634 & 0,327564 & 0,389706 & Matang & Benar \\
\hline RANGE & $\begin{array}{c}0,097502- \\
0,115634 \\
\end{array}$ & $\begin{array}{c}0,324949- \\
\mathbf{0 , 3 5 7 5 3 4} \\
\end{array}$ & $\begin{array}{c}0,365428- \\
0,39382\end{array}$ & \multicolumn{2}{|c|}{ Matang } \\
\hline Mangga 6 & 0,104472 & 0,330665 & 0,372012 & $\begin{array}{l}\text { Setengah } \\
\text { Matang }\end{array}$ & Benar \\
\hline Mangga 7 & 0,093296 & 0,315532 & 0,365563 & $\begin{array}{l}\text { Setengah } \\
\text { Matang }\end{array}$ & Benar \\
\hline Mangga 8 & 0,090502 & 0,304611 & 0,343395 & Matang & Tidak Benar \\
\hline Mangga 9 & 0,100693 & 0,305874 & 0,34247 & Matang & Tidak Benar \\
\hline Mangga 10 & 0,087285 & 0,302919 & 0,339892 & Matang & Tidak Benar \\
\hline RANGE & $\begin{array}{c}0,087285- \\
0,104472\end{array}$ & $\begin{array}{c}0,302919- \\
0,330665\end{array}$ & $\begin{array}{c}0,339892- \\
0,372012\end{array}$ & \multicolumn{2}{|c|}{ Setengah Matang } \\
\hline Mangga 11 & 0,14757 & 0,098314 & 0,344266 & Mentah & Benar \\
\hline Mangga 12 & 0,145385 & 0,115814 & 0,336843 & Mentah & Benar \\
\hline Mangga 13 & 0,149068 & 0,113188 & 0,337977 & Mentah & Benar \\
\hline Mangga 14 & 0,13591 & 0,112255 & 0,334552 & Mentah & Benar \\
\hline Mangga 15 & 0,136501 & 0,106563 & 0,32841 & Mentah & Benar \\
\hline RANGE & $\begin{array}{l}0,13591- \\
0,149068\end{array}$ & $\begin{array}{c}0,098314- \\
0,115814\end{array}$ & $\begin{array}{c}0,32841- \\
0,344266\end{array}$ & \multicolumn{2}{|c|}{ Mentah } \\
\hline
\end{tabular}

Berdasarkan tabel hasil pengujian buah mangga Garifta Merah dapat diketahui bahwa nilai $\mathrm{H}$ pada buah mangga Garifta Merah mentah lebih besar yaitu antara 0,13591 0,149068 dibandingkan buah mangga Garifta Merah matang yang memiliki nilai diantara 0,097502 - 0,115634. Karena pada nilai $0,13591-0,149068$ terjadi proses pematangan yang mempengaruhi warna kulit buah mangga Garifta Merah. Nilai S pada buah mangga Garifta Merah mentah sebesar 0,098314 - 0,115814, buah mangga Garifta Merah setengah matang sebesar 0,302919-0,330665, dan buah mangga Garifta Merah matang sebesar 0,324949 - 0,357534. Untuk buah mangga Garifta Merah mentah memiliki nilai terbesar karena pada buah mangga Garifta Merah mentah memiliki intensitas yang tinggi. Nilai I pada buah mangga Garifta Merah mentah sebesar 0,32841 - 0,344266, buah mangga Garifta Merah setengah matang sebesar 0,339892 0,372012, dan buah mangga Garifta Merah matang sebesar $0,365428-0,39382$. Berdasarkan data tersebut, menunjukkan bahwa nilai I buah mangga Garifta Merah matang lebih rendah dibandingkan buah mangga Garifta Merah mentah dan buah mangga Garifta Merah setengah matang. Hal ini dikarenakan tingkat kecerahan buah mangga Garifta Merah matang sangat rendah.

Setelah mendapatkan hasil dari pengujian, kami melakukan pengukuran tingkat keberhasilan klasifikasi pada program ini. Untuk mengukur tingkat keberhasilan klasifikasi, kami menggunakan Confusion Matrix. Tabel 3 menunjukkan Confusion Matrix 3x3.

TABEL IV

CONFUSION MATRIX

\begin{tabular}{|l|c|c|c|}
\hline & \multicolumn{3}{|c|}{ Prediksi } \\
\hline Aktual & Matang & $\begin{array}{l}\text { Setengah } \\
\text { Matang }\end{array}$ & Mentah \\
\hline Matang & 5 & 0 & 0 \\
\hline Setengah Matang & 3 & 2 & 0 \\
\hline Mentah & 0 & 0 & 5 \\
\hline
\end{tabular}

\section{a. Accuracy}

Untuk menghitung accuracy, kami melakukan kalkulasi menggunakan persamaan (5).

$$
\text { Accuracy }=\frac{\text { TP }}{\text { Jumlah Data }}
$$

Kemudian masukkan data yang diperlukan dalam rumus tersebut.

$$
\text { Accuracy }=\frac{5+2+5}{15}=\frac{12}{15}=0,8
$$


Accuracy $=0,8 * 100 \%=80 \%$

Jadi, tingkat accuracy dalam program kami adalah $80 \%$.

\section{b. Precision}

Formula yang digunakan untuk menghitung nilai precision ditunjukkan pada persamaan (6).

$$
\text { Precision }=\frac{\mathrm{TP}}{\mathrm{TP}+\mathrm{FP}}
$$

TABEL V

HASIL PRECISION

\begin{tabular}{|l|c|c|c|}
\hline & Matang & $\begin{array}{l}\text { Setengah } \\
\text { Matang }\end{array}$ & Mentah \\
\hline TP & 5 & 2 & 5 \\
\hline FP & 0 & 3 & 0 \\
\hline Precision & $5 /(5+0)=\mathbf{1}$ & $2 /(2+3)=\mathbf{0 , 4}$ & $5 /(5+0)=\mathbf{1}$ \\
\hline
\end{tabular}

Setelah mendapatkan hasil precision dari masing-masing kelas, kemudian menjumlahkan semua nilai dan membaginya dengan jumlah kelas.

$$
\begin{gathered}
\text { Precision }=\frac{1+0,4+1}{3}=\frac{2,4}{3}=0,8 \\
\text { Precision }=0,8 * 100 \%=80 \%
\end{gathered}
$$

Jadi, untuk nilai precision pada program kami adalah $80 \%$.

c. Recall

Rumus yang digunakan untuk menghitung nilai recall ditunjukkan pada persamaan (7).

$$
\text { Recall }=\frac{\mathrm{TP}}{\mathrm{TP}+\mathrm{FN}}
$$

TABEL VI

HASIL RECALL

\begin{tabular}{|l|c|c|c|}
\hline & Matang & $\begin{array}{l}\text { Setengah } \\
\text { Matang }\end{array}$ & Mentah \\
\hline TP & 5 & 2 & 5 \\
\hline FN & 3 & 0 & 0 \\
\hline Recall & $\begin{array}{l}5 /(5+3) \\
=\mathbf{0 , 6 2}\end{array}$ & $\begin{array}{l}2 /(2+0)= \\
\mathbf{1}\end{array}$ & $\begin{array}{l}5 /(5+0)= \\
\mathbf{1}\end{array}$ \\
\hline
\end{tabular}

Sama seperti precision, setelah mendapatkan hasil recal untuk setiap kelas, kemudian menjumlahkan semua nilai dan membaginya dengan jumlah kelas.

$$
\begin{gathered}
\text { Recall }=\frac{0,62+1+1}{3}=\frac{2,62}{3}=0,87 \\
\text { Recall }=0,87 * 100 \%=87 \%
\end{gathered}
$$

Jadi, untuk nilai recall dalam program kami adalah $87 \%$.

\section{KESIMPULAN}

Berdasarkan hasil penelitian klasifikasi kematangan buah mangga Garifta Merah. Selain mengklasifikasi kematangan buah mangga Garifta Merah secara manual, kami juga memakai software MATLAB R2015a yang terdapat program menggunakan metode transformasi ruang warna HSI dimana nilai RGB diubah kedalam nilai HSI.

Dengan menggunakan 15 data uji diperoleh 12 data yang sesuai dengan datanya dan 3 data tidak sesuai dengan datanya. Didapatkan hasil tingkat accuracy, precision, dan recal beturut-turut adalah $80 \%, 80 \%$ dan $87 \%$. Dari nilai persentase tersebut dapat ditarik kesimpulan bahwa dengan metode yang kami pakai, dapat digunakan untuk mengklasifikasi kematangan buah mangga Garifta Merah.

\section{DAFTAR PUSTAKA}

[1] Y. Oktavianto, Sunaryo, and A. Suryanto, "Kabupaten Kediri Characterization Of Plant Mango ( Mangifera Indica L .) Cantek, Ireng, Empok, Jempol," J. Produksi Tanam., vol. Volume 3, no. 2, pp. 91-97, 2015.

[2] A. Irfianti and W. B. Sunarharum, "Eksplorasi Karakteristik Kimia Dan Fisik Serta Komponen Gula Pada Mangga Garifta (Mangifera indica)," J. Pangan dan Agroindustri, vol. 7, no. 2, pp. 47-52, 2019, doi: 10.21776/ub.jpa.2019.007.02.5.

[3] M. D. Ariyantini, "Staphylococcus aureus", Digital Repository Universitas Jember, 2017.

[4] S. Jatmika and D. Purnamasari, "Rancang Bangun Alat Pendeteksi Kematangan Buah Apel Dengan Menggunakan Metode Image Processing Berdasarkan Komposisi Warna," J. Ilm. Teknol. Inf. Asia, vol. 8, no. 1, pp. 51-58, 2014.

[5] O. N. Shpakov and G. V. Bogomolov, "Technogenic activity of man and local sources of environmental pollution," Stud. Environ. Sci., vol. 17, no. C, pp. 329-332, 1981, doi: 10.1016/S01661116(08)71924-1.

[6] M. Swedia, Ericks Rachmat \& Cahyanti, "Algoritma Tranformasi Ruang Warna," Vis. Bassic6, Vis. Basic.NET dan java, pp. 1-94, 2010.

[7] H. Sanusi, S. H. S., and D. T. Susetianingtias, "Pembuatan Aplikasi Klasifikasi Citra Daun Menggunakan Ruang Warna Rgb Dan Hsv," J. Ilm. Inform. Komput., vol. 24, no. 3, pp. 180-190, 2019, doi: 10.35760/ik.2019.v24i3.2323.

[8] S. Sakir et al., "Penerapan Metode Transformasi Ruang Warna HSI untuk Mendeteksi Tingkat Kematangan Buah Pisang Berdasarkan Fitur Warna Citra Kulit Pisang," J. PASTI, vol. 14, no. 3, p. 243 , 2021, doi: 10.22441/pasti.2020.v14i3.003.

[9] H. Edha, S. H. Sitorus, U. Ristian, J. Rakayasa, and S. Komputer, "Penerapan Metode Transformasi Ruang Warna Hue Saturation Intensity ( Hsi ) Untuk Mendeteksi," J. Komput. dan Apl., vol. 08, no. 1, pp. 1-10, 2020.

[10] M. F. Fibrianda and A. Bhawiyuga, "Analisis Perbandingan Akurasi Deteksi Serangan Pada Jaringan Komputer Dengan Metode Naïve Bayes Dan Support Vector Machine (SVM)," J. Pengemb. Teknol. Inf. dan Ilmu Komput., vol. 2, no. 9, pp. 3112-3123, 2018.

[11] B. P. Pratiwi, A. S. Handayani, and S. Sarjana, "Pengukuran Kinerja Sistem Kualitas Udara Dengan Teknologi Wsn Menggunakan Confusion Matrix," J. Inform. Upgris, vol. 6, no. 2, pp. 66-75, 2021, doi: $10.26877 /$ jiu.v6i2.6552. 